\title{
THE TEACHERS' VIEW OF THE METHODS USED TO INSPIRE PROFESSIONAL INTEREST ${ }^{1}$
}

\author{
ANNA BROCHHAUSEN
}

Supervising Principal, Indianapolis, Ind.

In the spring of 1907 , the Department of Education of Indiana University undertook an investigation to determine, if possible, the superintendents' and teachers' views of the methods employed to stimulate professional interest. The following questions were sent to teachers in different cities of New York, New Jersey, Missouri, Indiana, Minnesota, and Ohio:

I. What has aided and inspired you most as a teacher?

2. What assistance from superintendents (or supervisors) has been most helpful? Visits? Teachers' meetings? What kind of teachers' meetings have helped you most? Personal interviews?

3. Can you suggest anything more helpful to teachers than the means now employed?

To assure free expression, the teachers were requested to send their answers directly to Bloomington. About one hundred fifty answers were received. Whether the teachers really have expressed themselves frankly will probably be disputed. Nor can I decide the question. Our ideals are apt to speak when we record ourselves in black and white, but these ideals express our true selves.

This article will report a study of the teachers' answers under the following heads:

I. The teachers' attitude toward their work.

2. Their view of supervision.

3. Visiting other schools.

4. Teachers' meetings.

5. General suggestions.

${ }^{1}$ From the Pedagogical Seminary of Indiana University, J. A. Bergstrom, director. 
I. Judging from the answers received, there is among teachers a prevailing spirit of earnestness and serious appreciation of the great responsibility resting upon them. They show a religious attitude toward their work, together with an intense desire for self-improvement. More than half the answers say that the greatest inspiration comes to the teacher from the children. They speak as if they were commissioned to promote the betterment of humanity. One calls herself a "Crusader against ignorance." All feel it a privilege to be of help, and ask in almost an injured tone, "Could any other inspiration be needed to make us realize that we have chosen the highest profession-the molding of the lives of the young?" Frequently an answer is stated thus: "If I could know that the boys and girls leave me a little better prepared for citizenship, for the duties of manhood and womanhood, I would feel that my efforts have not been in vain. Let each teacher have a deep and abiding love for each soul intrusted to her care and the knowledge of duty well done will bring joy and courage to continue." Numerous replies are as follows :

"That which has aided and inspired me most as a teacher has been the happiness derived from my contact with the children."

"The response, sympathy, and friendship given by the pupils."

"The encouragement received from pupils when they have grown several years older and they express their gratitude for the help received from me, while in my schoolroom, has aided and inspired me most."

These answers prove that most teachers are keenly sensitive to their duty and responsibility, and humbly appreciate their power to do good. Part of this inspiration which they receive from the children is possibly due to the feeling of success. in their work. Indeed, several acknowledge this fact:

"The greatest inspiration to me is to see results from my work with the children."

"The encouragement that comes when one's own teaching shows successful results."

"This may seem egotistical: that inspiration is found in the 
successful termination of one's own efforts, but nevertheless I believe it is true."

Psychologically, it is undoubtedly true; but these teachers at the same time mention their love for children, and in their replies show devotion to their work.

Accompanying this religious attitude is a strong desire for higher scholarship. They feel the need of better preparation. One woman replies to Question 3, "A more rigid requirement for a license. Before a young person enters the teaching profession, he ought to be quite familiar with what is being done and what has been done by the most proficient men and women of the profession. He ought, also, to be a very close student of human nature. Such a student as only a somewhat extended study of psychology and pedagogy can produce." Another writes: "Require higher qualifications." Many long for the opportunity to travel and attend schools, and suggest that scholarships, like those given in Indianapolis, be awarded talented teachers.

In most cities there are classes, reading-circles, literary clubs, formed among the teachers. A letter received from a woman who once taught, speaks forcibly against these intellectual stimuli. She says: "The pleasure of study comes not from outside pressure." This truth is self-evident, but the history of these organizations proves that they originated among the teachers themselves. Upon inquiry, Superintendent Small of Providence, R. I., learned that two-thirds of the high-school and grade teachers had been studying either at the Rhode Island School of Design, or Brown University. "The general feeling of these men is that study is necessary for their own life and growth. As one puts it, he "wants the tonic that comes from outside study."

Superintendent Small goes on to say, "It is surprising to what an extent mood has carried these teachers in their studies. Some have pursued systematic work for ten, fifteen, or twenty years, and they are still working." To the question, "Should teachers be required to present evidence of increased scholarship?" he answers, "No. The mood for increased scholarship is inherent in the good teacher."

This strain which teachers feel, I believe, is not due so much 
to the work which they do, as to the nervousness caused by examinations. Some teachers are evidently taking university extension courses at the same time that they attend institutes and readingcircles. They must take the examination for their university credit as well as the state examination. In general, a teacher who is ambitious enough to wish to do university work will see to it that he is well informed in the subjects he is expected to teach. He will gain a great deal more from classwork than from a superficial preparation for examination. As one teacher states: "A large majority of the teachers here are availing themselves of the educational courses extended by the college in our vicinity; and while following this line of work, are suddenly confronted by the reactionary movement on the side of state officials toward a return to the former periodic examinations for 'teachers' license.' If a teacher who is a student keeps in close touch with the pupils by being herself a learner, why should she not be accorded recognition for her college credits while climbing the hill, as well as after she has reached the top? Yes, more credit! Could not the colleges and universities act in conjunction with the state board of education in the grading of a teacher's standing? If such an arrangement could be worked out and put into operation, it would relieve many of us from the feeling of being goaded on all sides." This seems a reasonable request and deserves consideration.

A more ideal spirit than the combination of these two, the devotion spoken of above and this striving "mood" as a basis for the profession, can scarcely be imagined, and this is certainly a striking feature of the answers received.

2. Teachers have expressed themselves quite freely about supervision. From their answers, I conclude that practically none think that it can be dispensed with. It may be that they think otherwise, but only one speaks of the danger of oversupervision, and volunteers the remedy of having a supervisor for a month or six weeks about twice a year. Radically opposed to this teacher's view are those who state that each building should have its own supervisor, and those who say, "They (the supervisors) ought to come oftener and stay longer." 
There is a general agreement in the fact that successful supervision depends upon the personality of the supervisor, or the superintendent. One goes so far as to say, "The influence of their visits depends nine-tenths on their personality." Another remarks, "Superintendents and principals should be persons of strong personality; of such faith in the work that we constantly feel a desire to do better." One claims that the greatest need today is inspiration from earnest leaders.

The characteristics of supervisors which receive favorable mention are enthusiasm and sympathy, as the following quotations show :

"Coming in touch with one who put her whole heart into her work has been a source of great inspiration to me. She was so enthusiastic that one could not be in her presence long without catching her spirit."

"One help I have always had when discouraged-my principal. She does not know what despondency means, nor can I when she talks to me, for in every storm her eyes can see the haven."

That supervisor is fortunate, indeed, of whom the following has been said, "My principal has a very pleasing way of offering her criticism. I do not realize at the time that my methods are being criticized. I try her suggestions because they are given as such, and find that her way is better. If she had done otherwise I should have been discouraged."

These quotations suffice to show the appreciated qualities of supervisors. Probably the greatest mistake of supervisors is lack of giving enough encouragement. It is sad that a teacher quotes from Dr. Hillis' Quest of Happiness, "This is an age of harsh judgments, cruel criticisms, and brutal blamings." Another puts it more mildly by saying, "The superintendent can be of great assistance by talking with the teacher about her work and giving her a word of praise when she deserves it." Still another says, "The fact that he always spoke a word of encouragement in regard to some point of success, at the same time that he pointed out mistakes, inspired me to accomplish better work. This I believe is very important in helping teachers." 
"A little commendation from a supervising officer does much in the way of help. The average inexperienced teacher has not much confidence in her ability and she needs it before she can succeed to any great degree. I remember very well a time in my early years of teaching when I received a little commendation from a conservative person, in whose judgment I had great confidence. It was like a tonic. I think it helped me to grow in my profession more than all the criticism that was ever given me. Criticism is bad enough when it is coupled with a little commendation, but it is positively deadening without it. Under commendation, and not criticism, one finds his power."

Perhaps these quotations are convincing enough to show how much the teachers feel the absence of encouragement from conferences with supervising officers. They feel most keenly haughty, overbearing conduct on the part of supervisors. Note this reply, "In personal interviews more help is obtained by the sympathetic appreciation of a supervising officer than by supervisory airs and a general attitude of criticism." One emphatically states that "children at once detect a critical attitude." Another says, "Visits are helpful when the supervisor is sympathetic and enters into the work, and when he talks over the work after the lesson. The supervisor who is an inspector only, may help the system, but he is of little help to the individual teacher." Another asks, "Could not the supervisor give more attention to environment and work with the teachers rather than over them. In case of weakness could he not help them even as they strive with children to know the cause of failure, and to remove the obstacle?"

I believe that this is exactly what supervisors strive to doto study the special power and need of the individual teacher; to be of help in developing every talent, and in overcoming difficulties. If they fail it is not due to lack of effort. These same things about which the teachers have complained have given superintendents and supervisors much occasion for thought. This fact would be acknowledged if all teachers could have heard Miss Harris, supervisor of schools in Rochester, N. Y., when she spoke to the superintendents at Louisville. In her paper she 
answered every criticism of the above quotations. She says, "The supervisor is not to sit in judgment, or to act as a disciplinarian; but he must be a sympathetic counselor who will guide the young teacher into right ways of teaching, and the older teachers, who do not understand the meaning of the course of study, to a wiser and clearer interpretation of the same.

"The function of the supervisor is not that of a police officer, nor of a detective to spy out weak teachers, nor even that of a critic; but primarily that of a helper and guide.

"The supervisor needs to carry into every classroom: one measure of ability to put himself in the teacher's place ... . two measures of the saving sense of humor; three measures of appreciation for the effort put forth; four of timely suggestion; and five of stimulating words of encouragement and commendation."

As heartily as I believe in the excellent spirit of most teachers, I believe that the above quotations from Miss Harris's paper express the spirit of most supervisors and superintendents.

The teachers in their replies generally acknowledge that their greatest help from supervisors comes to them through personal interviews:

"By far the greatest assistance that comes to me is from my principal, and that chiefly through personal interviews. His sympathy, appreciation, and ever-ready helpfulness are of untold value."

"The greatest aid to me as a teacher has been the help given me by my principal. She has always criticized my work in the form of suggestion."

"Personal interviews in which definite lines of improvement were suggested, so that a certain result could be worked for, were most helpful."

One teacher offers as a suggestion, "More personal interviews with supervisors after their visits, when points good and bad would be made."

That these interviews ought to be frank seems an unnecessary statement, yet some teachers feel that they are not so. One remarks that "personal interviews are rarely honest;" and an- 
other states that, "A superintendent or supervisor who can get a teacher to talk to him of her problems, as she would to a fellowteacher; and who instead of talking all around and outside the subject, or acting as if he would rather not be bothered, can and will give advice that 'will work,' is one most helpful to the individual teacher."

One feature of a supervisor's visits needs consideration, viz., that of interrupting the recitation. Though some consider it helpful, others strongly disapprove. One says, "The superintendent has helped me by visiting my school and taking part in a helpful way;" another that, "Visits in which supervisors and superintendents take part in recitations, followed by personal interviews when there has been perfect frankness on the part of both, are most helpful." Opposed to these views is the following: "I think supervising officers of all kinds, whether principals, supervisors, or superintendents, should be prohibited from going into any room where a recitation is going on, and addressing the teacher or class until the lesson is ended, or until the teacher gives some intimation that such a thing would be welcome. I think the average superintendent is thoughtful in regard to this point, but many principals are not. They do not recognize what someone has indicated as the 'sacredness of the recitation." "

No doubt, interruptions, which can be interpreted by the pupils as adverse criticism upon the teacher, ought never to occur. On the other hand, limited time prevents the supervisor's having a conference with each teacher after his visit. Therefore, in the beginning of the year, the supervisor can explain to his teachers that some time by a mere question during the recitation he can give a suggestion. If, however, the teachers prefer otherwise, their wishes will be respected. Some superintendents adopt the plan of writing out criticisms or suggestions and leaving them on the teacher's desk. Their writing in the presence of the children, however, disconcerts a self-conscious teacher. It has been my experience that it often strengthens the pupil's confidence in the teacher to commend at the close of a recitation. The teacher surely understands that the compliment is for her, while the pupils are pleased since they take part of the "well 
done!" to themselves. This generally produces a very happy result.

In the answers the teachers repeatedly express the desire that the supervisors take their classes for them. This is most helpful to them since the supervisor or superintendent teaches those children with whom the teacher is accustomed to work. To quote from two replies: "I cannot think of anything more helpful to me than my supervisor's conducting a lesson for me."

"It seems to me that it would be a great help to teachers if the supervisors would conduct a lesson as they would like to have it done by the teachers."

No doubt this method of giving help has one advantage, viz., the teacher observes a person of wide experience meeting the conditions which he is trying to manage; yet the teacher must recognize certain disadvantages:

In the first place, it is almost impossible for a supervisor of a thousand or more children to know the individual names. This immediately puts a gulf between him and the class.

Second, he cannot know the individual minds as well as the regular teacher.

Third, the children are not accustomed to the supervisor's manner of questioning.

And fourth, the supervisor has not seen the successive lessons leading up to the lesson he is to give. Consequently, in the preparatory step he is apt to call for knowledge which the children do not have. He deems it necessary to teach what he supposed already taught, and does not reach the step the teacher expected. As a result some teachers are apt to pronounce the recitation a failure.

In the report thus far, I have tried to present what many teachers think of the individual help received from supervisors. Of the means employed to help teachers collectively, "visiting other schools" and "teachers' meetings" are most frequently mentioned.

3. I judge from the answers that teachers regard visiting as the best of all the methods for inspiration, especially if they see 
a "successful teacher under every-day conditions." I quote from several replies:

"My visits to other schools have been most helpful when the teachers had regular work. I want to see errors made by the pupil, and see the teacher deal with them. Perfection is uninteresting and valueless, unless one can see how it was attained."

"Actual teaching that I have seen has helped me more than all talks. If some means could be devised by which teachers could see excellent work, I think they would be helped much more than by lectures."

"Visiting other schools, whether good or bad, has helped me to see the need of my own, to correct faults, and to strive for better results. Theory is good, but nothing can quite equal the seeing and doing."

"I have received my greatest and most inspiring help from visiting good schools. I mean by the really good school, one in which the teacher's love for her profession and love for the children are manifest in her work-where children's minds are developing in a fine, harmonious atmosphere. There isn't anything that anybody can tell us that is half so great a thing as this-actually seeing it done, naturally and beautifully, under the charm of someone who knows just how to do it, and who loves to do it."

"Visits are always helpful. I believe the observation of specially prepared lessons quite good. It sets a standard toward which to work. But even though the work observed be ordinary, it furnishes food for thought. Our very errors may be forcibly brought to us when observed in another."

Some answers lead me to think that there is a great deal of haphazard visiting done, from which the teachers get little help. Many express a desire for "directions for visiting," others, a wish that they might visit their own grade in company with other teachers, and that the observation might be followed by a discussion.

Beside the general idea of observing the work of someone else, the definite purpose of the visit should be made clear to the teacher before he is sent. A superintendent has one of two 
objects in mind when he sends teachers to visit, either to give inspiration to a number of teachers by having them observe unusually good work, or to give help to an individual teacher in a particular line.

In the first case, the teachers derive the greatest value when they visit an unusually strong teacher who accomplishes his results artistically. They should know what things to note-the teacher's manner, voice, questioning; the amount accomplished in a recitation, etc. At about a quarter, or half-past eleven, the pupils should be dismissed and a conference held with the teacher visited. This discussion, opened by the superintendent or his representative, followed by the teachers' expressing the definite help received, and questioning the how and why of method, throws a searchlight on the work observed.

When an individual teacher is sent to visit, his particular need should be especially considered. If his weakness lies in organization, the school chosen for his observation should be particularly strong in organization; if he lacks ingenuity, he should visit a teacher of inventive genius. Before the visit he ought to be told wherein he fails. The visit is most valuable, if he is accompanied by the superintendent or supervisor. Some teachers mention that they get more if the supervisor goes with them, and afterward talks of the work observed. If it is possible to accompany a teacher, a conference should follow the visit, to ascertain if he actually has seen what he was sent to see.

In every case teachers should know where they are to go. If left to chance they often return irritated to their own work, feeling that the hours were wasted. Furthermore, some of them need instruction in how to gain the most from visiting.

One teacher remarks that, "The right kind of visitor is an encouragement to the teacher." This leads me to ask, what is the right kind of visitor? It seems to me that it is neither he who comes to see only the good (which seems to be one teacher's idea of visiting), nor he who comes to find fault; but rather he who comes with a scientific interest to study the moral and spiritual atmosphere of the schoolroom, and the teacher's method of instruction. Therefore visiting is professional not personal. 
The visitor comes to examine and to learn. In the attitude of the learner, he welcomes and rejoices in all that is good and weighs method in the spirit of the student, not that of the faultfinder. If at the close of the visit the guest expresses gratitude for his privilege, points out what he liked and states in what way he has been helped, he may without fear of being misunderstood ask a question as to why this or that was done. Thus both teachers begin to weigh the merits of their respective methods. The exchange of experience is mutually helpful. This spirit of sympathetic interest is like the gift that blesses him who gives and him who receives.

4. From the answers received, I conclude that teachers' meetings, as a means of inspiration, rank next to visiting. Here again, superintendents may find encouragement in the assurance that every kind of teachers' meeting has been an inspiration to some individual. Though "a large meeting to hear some splendid address" has helped some more, others wish that there might be smaller circles where everyone would feel free to express himself.

There is a general agreement that the grade meetings are most helpful, especially when they consist of lessons given by teachers, followed by discussions something like "experience meetings," in which they compare notes and discuss individual problems. Again the teachers voice the desire to see "practical schoolroom work with average children," for many of them answer the question, "What kind of teachers' meetings have helped you most?" thus :

"The teachers' meeting where the manner of doing the work is demonstrated in regular class recitation, and not a 'show,' or 'cut-and-dried,' 'polished-till-it-shines' lesson; and then an open discussion of its merits and its faults."

"Those in which I have seen the regular class work done, and in which children make mistakes, so that I may see how others overcome them."

Hence some suggest that advanced work be presented in these lessons. One teacher offers a programme:

a) Outline of points to be made in the hands of the teachers. 
b) Class demonstration by one of the regular teachers.

c) Discussion of large points in light of demonstration.

d) General discussion and concrete application to regular work cited by teachers.

The statement, "We have too much theory and not enough demonstration," made by a teacher summarizes fairly well the teacher's feeling about many of the meetings.

From the study of the answers received, I conclude that in larger places there should be a grading of teachers' meetings, i. e., there must be separate meetings for inexperienced and experienced teachers. Many of the latter comment upon teachers' meetings thus: "They are helpful to young teachers." If we combine some of the suggestions sent in, we may find a partial solution for the difficulty. Might the experienced teachers choose such subjects for these meetings as have for their fundamental principle self-activity in educational research?

A word needs to be said about the number of meetings and the time of holding them. A teacher's strength is greatly taxed when more than one meeting a week is held, or when a meeting continues several hours after the close of school. One teacher remarks that she receives little help from teachers' meetings because they are always held Friday nights after school, and that then she is "too tired to take in anything."

Since the purpose of these meetings is to help the teachers, their physical ability to receive that help must be considered in the arrangement of the schedule of meetings:

First, the teacher's mind is full of so many things in the beginning weeks of school, that many points of a meeting are absolutely lost.

Second, after April, he is so worn out with the year's work that meetings are overburdensome. Consequently, he brings little or no inspiration from them into the schoolroom.

Hence, the best time for meetings is from about the middle of October to the middle of April, with a cessation during the time the children are being tested. Then the teacher has all that he can do to mark papers and prepare lessons to clear up hazy points in the children's minds. 
5. Of the many other helps, such as the teacher's associations, lectures, books, etc., many teachers have expressed their appreciation. They resent the narrowness in the choice of subject, however. One says, "In order that our interests and knowledge may be broad, the lectures we attend should not all bear directly upon our profession;" and several say they do not enjoy the study of books that are "thrust upon them." They desire a voice in the matter of selection.

Nearly all the suggestions offered in answer to question 3 are embodied in the above report. Higher salaries, fewer pupils, shorter hours receive mention. These are recognized everywhere as helpful, and will in the course of time be in effect. Therefore, I omit a discussion of them here. One suggestion expressed by several I do wish to call attention to, i. e., a co-operative planning of the curriculum. "It would increase interest through participation. All teachers criticize the course of study more or less, but for the most part unconsciously. I think it (the co-operative planning) is the way to get the best work for the children, and a needed means of inspiring teachers."

It was difficult to summarize the replies received, since the teachers' manner of expression is so different. However, by taking some liberties I have been able to classify them. All answers relating to the children: as for example, "watching the development of the children," "love for children," "a sense of the power to do good," etc., have been grouped under the "inspiration received from children." Allowing for this freedom in arrangement the following gives a survey of the answers received:

Seventy-nine teachers say their greatest inspiration comes to them from the children.

Of the means employed, eighty-four acknowledge that visiting other schools has been of help; while some say that visiting has been most inspiring, others say that it has always been of help. Only one says she receives little help from visiting.

In speaking of teachers' meetings: seventy-eight regard the grade meetings as most helpful and more than half of these 
say that the meetings are most helpful because of the model lessons given; seventeen speak of the help received from general meetings; and nine, from building meetings.

Every answer contains something about supervision. Ninetysix speak favorably of personal interviews; two, against them. Forty consider the supervisor's conducting a lesson of most help. Twenty-eight express their gratitude for words of encouragement or appreciation. Six speak especially of inspiration from enthusiastic leaders. Twelve criticize an overbearing attitude in a supervisor, and two complain against too much urging.

Forty-six write of inspiration received from strong personalities, either of supervisors, lecturers, or former teachers.

Thirty-three speak of help and inspiration received from literature, pedagogical books, and current magazines.

Five suggest that teachers need more reference books.

Thirty-two teachers speak of inspiration received at lectures; twenty-four, of the gain through coming in contact with earnest workers at county, state, and national associations. Three of these speak especially of the National Educational Association; ten, of the help received at institutes. Two who speak against institutes do so because of the length of the meetings. If the lectures were given at different times through the year, they feel that the value would be greater. Three other answers suggest closer confederations or organizations among teachers.

Sixteen teachers assert the necessity for a broader outlook; seven of these, that a teacher needs more opportunity for study and travel.

Eighteen tell of help received from normal schools; and five, from work in colleges.

Fourteen express appreciation of help received through intercourse with other teachers.

Nine tell of co-operation of parents as helpful; three of whom recommend parents' meetings as an inspiration.

Five speak of the effort which the intense desire to become a "good teacher" has stimulated; one of these says it was aroused through exhibitions.

Six tell of the great help a well-organized course of study 
has been; though nine others wish that there might be a better planning, through the co-operative work of teachers with superintendents and supervisors.

Of the other suggestions received, six recommend that greater freedom be given the teacher; eight, higher salaries; five, fewer pupils; three, special schools for defective or incorrigible children; three, fewer examinations; two, that textbooks for children be made more simple; one, shorter hours; one, a larger social life. ${ }^{1}$

${ }^{1}$ I wish to express my appreciation and gratitude to the superintendents and teachers who answered the questions sent them. 